HUMANAS E SOCIAIS

V.9 * N.2 • $2021 \cdot$ Fluxo Contínuo

ISSN Digital: 2316-3801

ISSN Impresso: 2316-3348

DOI: 10.17564/2316-3801.2021v9n2p201-214
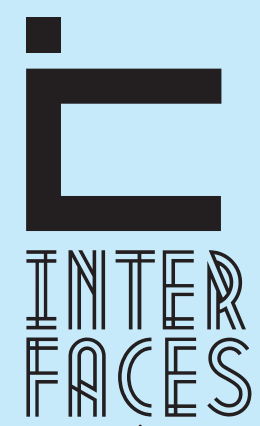

CIENTÍFICAS

\title{
IDENTIDADE E REPRESENTAÇ̃̃ES SOCIAIS DE JOVENS EM ASSENTAMENTOS RURAIS DA ZONA DA MATA DE ALAGOAS
}

IDENTITY AND SOCIAL REPRESENTATIONS OF YOUNG PEOPLE IN RURAL SETTLEMENTS IN THE ZONA DA MATA DE ALAGOAS

IDENTIDAD Y REPRESENTACIONES SOCIALES DE JÓVENES EN ASENTAMIENTOS RURALES EN LA ZONA DA MATA DE ALAGOAS

Géssika Cecília Carvalho da Silva ${ }^{1}$ Maria Eduarda Lino da Costa ${ }^{2}$

\section{RESUMO}

O presente trabalho objetivou compreender as percepções, vivências e representações sociais de jovens que moram em assentamentos rurais na Zona da Mata de Alagoas acerca de sua identidade, da agricultura familiar e dos processos de socialização nos âmbitos da educação, do trabalho, familiar e na participação política. Assim, percebeu-se que há uma baixa perspectiva de aumento da escolaridade e produção de renda no meio rural que é conflitante com o alto desejo de permanência desses jovens em sua comunidade. Ficou evidente que a grande maioria gosta de morar na comunidade rural e de participar do trabalho no campo; bem como é grande o percentual dos que pretendem dar continuidade ao trabalho dos pais nos assentamentos e continuar morando neles. A participação em associações e cooperativas é baixa, mas em movimentos sociais é mais representativa. Além do desejo de permanência no ambiente rural, é grande a expectativa de concretização dos objetivos, permanecendo nos assentamentos, mesmo que demande a implementação de políticas públicas por parte dos governantes.

\section{PALAVRAS-CHAVE}

Representações Sociais. Juventude. Assentamentos Rurais. 


\section{ABSTRACT}

The present work aimed to understand the perceptions, experiences and social representations of young people who live in rural settlements in the Zona da Mata de Alagoas about their identity, family farming and socialization processes in the fields of education, work, family and participation policy. Thus, it was noticed that there is a low prospect of increasing schooling and income production in rural areas, which is in conflict with the high desire for these young people to remain in their community. It was evident that the great majority likes to live in the rural community and to participate in the work in the field; as well as a large percentage of those who intend to continue their parents' work in the settlements and continue to live in them. Participation in associations and cooperatives is low, but in social movements it is more representative. In addition to the desire to remain in the rural environment, there is a great expectation of achieving the objectives remaining in the settlements, even if it requires the implementation of public policies by the government.

\section{KEYWORDS}

Social representations. Youth. Rural settlements.

\section{RESUMEN}

El presente trabajo tuvo como objetivo comprender las percepciones, experiencias y representaciones sociales de los jóvenes que viven en asentamientos rurales en la Zona da Mata de Alagoas sobre su identidad, la agricultura familiar y los procesos de socialización en los campos de la educación, el trabajo, la familia y la participación política Por lo tanto, se observó que existe una baja posibilidad de aumentar la escolarización y la producción de ingresos en las zonas rurales, lo que está en conflicto con el gran deseo de que estos jóvenes permanezcan en su comunidad. Era evidente que a la gran mayoría le gusta vivir en la comunidad rural y participar en el trabajo en el campo; así como un gran porcentaje de aquellos que tienen la intención de continuar el trabajo de sus padres en los asentamientos y continuar viviendo en ellos. La participación en asociaciones y cooperativas es baja, pero en los movimientos sociales es más representativa. Además del deseo de permanecer en el entorno rural, existe una gran expectativa de lograr los objetivos que quedan en los asentamientos, incluso si esto requiere la implementación de políticas públicas por parte del gobierno.

\section{PALABRAS CLAVE}

Representaciones sociales. Juventud. Asentamientos rurales. 


\section{INTRODUÇ̧̃̃o}

Atualmente, no contexto da juventude rural, muitos trabalhos abordam o processo de sucessão familiar e expectativas de vida dentro do meio rural, como se perfaz o perfil do atual jovem camponês e quais as suas perspectivas de vida no mundo pós-moderno. Estudos demonstram mudanças no padrão sucessório do meio rural; os jovens, cada vez mais, buscam oportunidades de vida no meio urbano, "entre os motivos apontados para a emigração rural estão, de um lado, os atrativos da vida urbana, principalmente em opções de trabalho remunerado (fatores de atração); e de outro lado, as dificuldades da vida no meio rural e da atividade agrícola (fatores de expulsão)" (BRUMER, 2006, p. 36).

Ao analisar o último Censo do Instituo Brasileiro de Geografia e Estatística (IBGE), realizado em 2010, considerando a faixa etária entre 15 e 29 anos, os jovens ocupam um quarto da população do país; do total, 84,8 \% deles vivem nas cidades e 15,2 \% no campo. Dentro da categoria "juventude", a juventude rural é vista "por uma ótica urbana que percebe o rural como um espaço de precariedade social, reforçando, mesmo que involuntariamente, o estigma sobre este segmento" (WEISHEIMER, 2009, p. 110).

A Agroecologia, enquanto ciência holística e interdisciplinar, aborda a problemática da juventude rural e da sucessão rural na agricultura familiar, além de todo o estudo envolvido na questão do êxodo rural, como um meio de obter o entendimento sobre processos socioespaciais no ambiente rural e o que atualmente põe em risco a continuação e a reprodução desses espaços, dos saberes populares, a manutenção desses saberes e a ressignificação da cultura camponesa e dos povos tradicionais a partir da dinâmica da sociedade moderna. No contexto da Agroecologia, a renovação das unidades de produção agrícola de base familiar significa a renovação e continuação dos saberes da comunidade.

A pesquisa em questão foi pautada no interesse de entender as perspectivas, objetivos e interesses dos jovens que vivem em assentamentos e comunidades rurais na Zona da Mata Alagoana (nos municípios de Murici e de União dos Palmares), para assim perfilar as identidades e representações sociais deste grupo. Assim, objetivou compreender as percepções, vivências e representações sociais de jovens que moram em assentamentos rurais na Zona da Mata de Alagoas acerca de sua identidade, da agricultura familiar e dos processos de socialização nos âmbitos da educação, do trabalho, familiar e na participação política.

\section{AGRICULTURA FAMILIAR E SUCESSÃO RURAL}

A história do Brasil é a história da luta pela terra. Desde o período colonial o poder nas terras Tupiniquins é correlacionado com a posse da terra e este processo histórico reflete diretamente na constituição agrária do país e nas atuais distribuições de terra.

O primeiro modelo latifundiário implantado aconteceu por meio da divisão do Novo Mundo em quinze grandes faixas de terra pela Coroa Portuguesa e entregue a doze donatários portugueses para colonização e exploração. A esses donatários ainda lhes cabiam a passagem de suas terras dos pais 
para os filhos, nasceram assim as conhecidas Capitanias Hereditárias. Depois do modelo das Capitanias Hereditárias rapidamente se desenvolve o Regime das Sesmarias, responsável pela instalação da plantation que perdura até hoje na colônia.

Por fim, o atual modelo de latifúndio, que foi forjado desde o período colonial, se concretiza no Brasil por meio da lei de terras $n^{0} 601$, de 18 de setembro de 1850, lei esta que depois da declarada "independência" da coroa portuguesa em 1822, estabeleceu a compra como único acesso possível à posse legítima da terra. Desse modo, as terras acabaram por permanecer em posse dos grandes proprietários latifundiários, que possuíam capital econômico para realizar a compra e excluíam a possibilidade de posse dos pequenos produtores e lavradores que trabalhavam nas terras.

O modelo de colonização latifundiária acabou por impedir que a população rural pobre obtivesse acesso à terra, caracterizando grande desigualdade no meio rural. Sob o modelo latifundiário e o sistema de monocultura, o Brasil reflete os problemas de desigualdade que resultam da adoção da produção nos moldes da agricultura extensiva.

Em 1964 surge o estatuto da terra (Lei n 4.504, de 30 de novembro de 1964), vigente até hoje. 0 estatuto foi criado com objetivo de garantir a reforma agrária e o desenvolvimento da agricultura no país. Atualmente pode-se constatar que o primeiro objetivo pouco saiu do papel, quanto ao desenvolvimento da agricultura quando relacionado ao agronegócio e financiamento dos grandes latifúndios continuou se consolidando grandemente no Brasil.

Segundo o IBGE, no Censo Agropecuário 2017, quase 70\% dos estabelecimentos agropecuários no Brasil tem entre 1 e 50 hectares e 17\% têm entre 50 e 10.000 hectares. Em Alagoas, segundo dados da Secretaria do Planejamento, Gestão e Patrimônio de Alagoas (SEPLAG, 2016), 64\% da área ocupada com agricultura no estado têm entre 100 e 1.000 hectares ou ultrapassam os 1.000 hectares. Estes dados retratam a desigualdade de acesso à terra e fazem com que se analise como o desenvolvimento da agricultura familiar é influenciado por este modelo e como isto vai refletir em questões como o êxodo rural e a sucessão familiar.

“No Brasil, a produção familiar sempre foi um setor marginalizado, disputando com o agronegócio exportador a atenção do poder público e o reconhecimento de sua importância para o desenvolvimento do país" (SEPLAG, 2016). A falta da aplicação efetiva das políticas públicas existentes, a mecanização do campo, a má distribuição de terras e os grandes pacotes tecnológicos que chegam ao meio agrícola historicamente fizeram e ainda fazem com que estes produtores muitas vezes não tenham condições de se autossustentar enquanto unidade de produção familiar.

Dos fatores que contribuíram para o êxodo rural, a mecanização é tida por diversos trabalhos que abordam historicamente esse processo como o principal fator de migrações definitivas, pois provocou a exclusão do pequeno produtor e este se viu atingido por uma política que mais favorecia o agronegócio. Esse fenômeno atingiu pessoas de todas as idades, pois famílias inteiras se mudaram neste período, tornando a área de produção rural uma área anecúmena.

Mas não se pode falar, de maneira geral, numa reversão da tendência observada desde 1940: a partir de então, a cada década, mais de um terço da população residente no meio rural no início do período migrava em direção às cidades. Durante os anos 1980 foram 
mais de 12 milhões de pessoas e, na primeira metade da década de 1990, o êxodo já atingiu 5,6 milhões de indivíduos. (ABRAMOVAY, 1999, p. 4).

O alto fluxo migratório aumenta a concentração nos grandes centros urbanos, principalmente nas periferias, que são geralmente os locais que mais recebem os indivíduos que migram em consequência do êxodo rural. Este movimento afeta o desenvolvimento da agricultura familiar e causa o inchaço urbano nas capitais, pois faltam investimentos e há reduzido planejamento do Estado na ampliação da infraestrutura urbana.

A partir deste cenário histórico, os movimentos sociais em prol da obtenção da posse de terras para agricultura familiar surgem com o objetivo de reverter a concentração latifundiária. As Ligas Camponesas se estruturam na década de 1950, possuindo como principal objetivo a organização dos trabalhadores rurais em busca de leis de reforma agrária, visando à redistribuição de terras. 0 movimento segue até 1964, período em que se instala no país a Ditadura Militar.

Após a ditadura, outros movimentos surgem, voltando a reivindicar o direito à terra, como o Movimento dos Trabalhadores Rurais Sem Terra (MST), que reivindica a realização da reforma agrária por meio da redistribuição de terras dos grandes latifúndios e o uso de terras improdutivas para o desenvolvimento da agricultura familiar, bem como geração de emprego e renda no campo. Além do MST, alguns grupos se destacam nesta conjuntura, são eles o Movimento de Mulheres Camponesas (MMC) e a Comissão Pastoral da Terra (CPT).

O MMC é um movimento autônomo, popular, feminista e de classe com cerca de 20 anos de existência formado por mulheres, em sua totalidade camponesas, que lutam pela igualdade de direitos, pelo fim de qualquer forma de violência, opressão e exploração praticada contra a mulher e a classe trabalhadora. Elas têm diretorias em 18 estados brasileiros e suas reinvindicações são pautadas na luta feminista e na luta pela transformação na sociedade (MMC BRASIL). A CPT é uma organização vinculada à Igreja Católica, que busca enquanto pastoral a retomada do trabalho de base junto aos povos da terra e das águas nos seus processos coletivos na conquista dos direitos e da terra; "a CPT foi criada para ser um serviço à causa dos trabalhadores e trabalhadoras do campo e de ser um suporte para a sua organização" (CPT, 2019).

É neste cenário histórico-social de concentração de terras e desigualdades que se faz necessário entender e discutir as dinâmicas ligadas à reprodução das unidades de produção familiar, o processo de sucessão familiar dentro destas unidades, em especial dentro dos assentamentos de reforma agrária e qual o papel da juventude neste espaço. Souza e Simonetti (on-line) atentam para necessidade da inserção dos jovens nos movimentos de resistência camponesa e de como a renovação das lideranças e o repasse do conhecimento das lutas de classe são essenciais para a continuação da reforma agrária no país.

A discussão acerca da sucessão geracional da família camponesa é prioritária para a continuidade dos movimentos sociais camponeses e de assentados, para a continuidade da reforma agrária e para a democratização da terra, pois não se trata apenas de sucessão da posse das propriedades agrícolas, mas trata também da reposição de lideranças e de dirigentes em todas as instâncias dos movimentos sociais, trata também da reposição da força de trabalho em assentamentos com relativo tempo de ocupação, nos quais os assen- 
tados então passando por um processo de envelhecimento; reposição essa que a luta pela terra e a reforma agrária exigem. (SOUZA; SIMONETTI, on-line, p. 3).

Além do tocante político, a inserção da juventude dentro da dinâmica da agricultura familiar é uma questão estratégica para o repasse e a continuação dos saberes populares camponeses, bem como a segurança e a soberania alimentar do país, pois cerca de $70 \%$ dos alimentos que chegam à mesa dos brasileiros são provenientes da agricultura familiar (MDA, 2017). Segundo o Ministério de Desenvolvimento Agrário (MDA, 2018), o faturamento anual da agricultura familiar é de cerca de US\$ 55,2 bilhões ao ano, o que coloca o Brasil, ainda, entre os dez maiores produtores mundiais apenas com a produção agrícola familiarnacional.

A problemática do êxodo rural juvenil, quais questões estão envolvidas neste processo, quais as consequências do êxodo para a agricultura familiar, como este jovem se vê e o que ambiciona para o seu futuro são objeto de pesquisa para muitos estudiosos. Esse êxodo rural muitas vezes acaba por deixar os estabelecimentos rurais sem sucessores e, segundo Brumer (2006), a sucessão familiar, no contexto da agricultura familiar, é considerada de extrema importância não só diretamente para os membros da família propriamente dita, como também para a reprodução destas unidades de produção no decorrer dos anos.

Segundo Abramovay e outros autores (2001), o meio rural está envelhecendo e se masculinizando. Os estudos apontam diversas condições que estimulam, ou não, a permanência do jovem no campo, entre elas estão a escolaridade e a possibilidade de renda no meio rural.

A escolha profissional dos jovens agricultores é determinada por um conjunto de fatores, dos quais os mais relevantes são suas expectativas de geração de renda na unidade paterna comparadas com o que imaginam ser possível alcançar inserindo-se em mercados de trabalho assalariado. (ABRAMOVAY et al., 2001, p. 4).

Ainda nos estudos Abramovay e outros autores (2001), dados demonstram que um menor grau de escolaridade influencia na tomada de decisão sobre permanecer na unidade de produção agrícola; aqueles que possuem menor grau de formação tendem a permanecer no campo, e este é um padrão tão forte que mesmo os estados com melhor grau de escolaridade não fogem à regra no Brasil.

Segundo o Censo Agropecuário 2017 (IBGE, 2017), no Brasil 15,44\% dos produtores nunca frequentaram a escola, 12,60\% frequentaram classes de Alfabetização e 23,74\% frequentaram o antigo primário (elementar) e apenas 12,65\% possuem Ensino Médio Regular e 5,55\% apresentam graduação. No estado de Alagoas, 24,14\% nunca frequentaram a escola, 25,66\% frequentaram classes de Alfabetização e $11 \%$ frequentaram o antigo primário (elementar), apenas 8,71\% possuem Ensino Médio Regular e 3,31\% apresentam graduação.

O gênero também é um fator decisivo quando se debate sobre aqueles que desejam, ou não, permanecer no meio rural. A maior parte das moças deseja uma inserção no meio urbano à permanência no meio rural, enquanto a maior parte dos rapazes acaba por desejar assumir a continuação da unidade de produção. 
Os migrantes rurais brasileiros são cada vez mais jovens e em seu interior o peso das moças é superior ao dos rapazes. [...] Em 1991, o número de rapazes na faixa de 15 a 19 anos é superior em $13 \%$ ao número de moças e, na faixa de 20 a 24 anos, 12\% superior. Mais recentemente, este processo de "masculinização do meio rural" vem atingindo não apenas o meio rural, mas também os pequenos municípios do interior (ABRAMOVAY et al., 2001, p. 4).

Segundo os resultados preliminares do Censo Agropecuário 2017, realizado pelo IBGE, 81\% do pessoal ocupado em estabelecimentos agropecuários no Brasil é homem, 19\% são mulheres e apenas 5\% deste total têm menos de 30 anos de idade. No estado de Alagoas existem 324 mil pessoas ocupadas em atividade agropecuárias; destes, $76 \%$ são do sexo masculino e $23 \%$ do sexo feminino. Ainda $62 \%$ dos produtores estão com faixa etária entre 30 e 60 anos e apenas $7 \%$ têm menos de 30 anos.

Os fatores de expulsão e de atração da atividade agrícola também estão relacionados à escolha de permanecer na unidade de produção familiar ou não. Segundo Brumer (2006), provavelmente, quando se toma a decisão de migrar, os fatores de expulsão são anteriores aos de atração

[...] entre os motivos apontados para a emigração rural estão, de um lado, os atrativos da vida urbana, principalmente em opções de trabalho remunerado (fatores de atração); e de outro lado, as dificuldades da vida no meio rural e da atividade agrícola (fatores de expulsão). (BRUMER, 2006, p. 36).

Na sociedade contemporânea é de grande importância pensar como a dicotomia do rural e do urbano se apresenta na vivência dos jovens que vivem em comunidades rurais, mas que também se inserem dentro de um mundo tecnológico e globalizado.

A sucessão da unidade de produção familiar é uma questão tida como inerente ao processo de reprodução social do campesinato, o que dentro do viés agroecológico se configura como a reprodução de costumes, saberes e tradições. Tendo em vista o conhecimento sobre os padrões migratórios e a perspectiva dos jovens sobre o meio agrícola são necessários estudos que analisem "o modo de vida, as relações sociais, as condições estruturais, as oportunidades de lazer e acesso as atividades agrícolas e não agrícolas, para jovens de ambos os sexos” (BRUMER, 2006, p. 41), buscando, assim, diminuir o êxodo juvenil das unidades de produção familiar e as questões ligadas à realocação dos migrantes nos grandes centros urbanos. Estas ações, consequentemente, aumentam as condições de desenvolvimento e criação de renda em áreas agrícolas e diminuem os fatores de expulsão.

\section{METODOLOGIA}

O estudo apoiou-se na necessidade de compreensão e problematização de como o jovem se vê e se sente no ambiente rural. Foram utilizados dados quantitativos em alguns momentos para compor o perfil dos informantes, porém o foco do trabalho recaiu, principalmente, sobre os aspectos qualitativos dos dados coletados. 
Assim, como primeira forma de coleta de dados realizou-se uma pesquisa bibliográfica e exploratória sobre o tema abordado. Em seguida, realizou-se a aplicação de um questionário com 32 (trinta e dois) jovens que residem nos assentamentos Dom Hélder Câmara e Padre Emilio April, situados nos municípios de Murici e de União dos Palmares, na Zona da Mata Alagoana.

\section{RESULTADOS}

Os informantes da pesquisa são jovens residentes nos assentamentos Dom Hélder Câmara e Padre Emilio April, situados nos municípios de Murici e de União dos Palmares, Alagoas, com idades entre 14 e 29 anos. Dos 32 respondentes, $47 \%$ são do sexo masculino e $53 \%$ do sexo feminino. Quanto ao estado civil, $22 \%$ se apresentaram como casados e $78 \%$ como solteiros. Ainda $28 \%$ declararam ter filhos.

Quanto à escolaridade, 41\% possuem o Ensino Fundamental II (do $6^{\circ}$ ao $9^{\circ}$ ), 19\% Ensino Médio Técnico, 37\% Ensino Médio Regular e apenas 3\% possuem graduação.

Dos respondentes, todos afirmaram que pretendem continuar os estudos. Assim, questionados sobre suas pretensões acadêmicas, 34\% desejam chegar a uma graduação e $22 \%$ almejam uma pós-graduação. Por outro lado, 38\% querem continuar até o Ensino Médio Regular ou Ensino Médio Técnico e $6 \%$ permanecerem com Fundamental II.

Com relação à identificação com o lugar que moram, 94\% dos jovens informantes dizem gostar da comunidade que residem, $3 \%$ não gostam e $3 \%$ dizem gostar "um pouco".

São diversas as justificativas para se gostar do assentamento, estas vão desde a luta dos seus pais na obtenção da terra para obter trabalho e sustento, como se percebe nas narrativas: "Nasci aqui e mim criei, desde a minha infância vejo a luta dos meus pais para conquistar o que temos, como não mim sentir bem em um lugar onde está toda minha historia de vida”; ou até a memória afetiva do lugar e a relação com a natureza: "Uma experiência maravilhosa, de estar em um lugar onde mim identifico da minha ancestralidade presente, o poder estar bem juntinho da terra, cuidar e proteger. É uma obra poder morar em assentamento e nunca perder sua essência de onde veio!”.

Outros justificam que na comunidade as relações sociais são mais fáceis que nos centros urbanos e que questões como habitação, segurança e alimentação influenciam na escolha do melhor lugar para se morar: "Porque é bom, não paga aluguel, aqui tudo que quer comer pode pegar e na rua tem que comprar"; "Eu gosto de morar aqui por que é tranquilo, é melhor que na cidade que tem roubo, e um bocado de negócio ruim”.

Aqueles que afirmaram gostar "um pouco" ou não gostar de morar na comunidade justificam que os assentamentos estão longe das "facilidades" dos centros urbanos e das opções de entretenimento: "Ter liberdade dentro do assentamento, mas não ter diversão que a cidade oferece"; "Porque tem pouca gente, é longe de tudo”.

No que se refere a suas contribuições na dinâmica familiar, 56\% dos jovens dizem participar "às vezes" dos trabalhos no campo dentro do lote da família, 35\% afirmam participar sempre e $9 \%$ não participam. Constatou-se que, daqueles que afirmam sempre executar os trabalhos no campo, $64 \%$ são do sexo masculino. 
Com relação aos afazeres domésticos, $62 \%$ afirmam que sempre os executa em casa, $22 \%$ dizem que "às vezes" e $16 \%$ afirmam que não colaboram nas atividades domésticas. Dos que afirmaram sempre executar tarefas domésticas, $80 \%$ são do sexo feminino.

Quando questionados sobre o interesse em dar continuidade ao trabalho dos pais nos lotes, $84 \%$ afirmam ter esta pretensão, $13 \%$ se posicionam como não tendo pensado na possibilidade e $3 \%$ afirmam não querer assumir a propriedade dos pais.

No que concerne à participação na comunidade, suas decisões e suas representações, $81 \%$ afirmaram que existe associação de moradores e/ou cooperativa no local onde moram e $19 \%$ negaram a existência. Apesar desse percentual que negou a existência de associação de moradores e/ou cooperativa, foi constatado que existe nas duas comunidades.

Mesmo existindo conhecimento da associação ou cooperativa por parte de $81 \%$ dos jovens, quando questionados quanto à sua participação nestas instituições, apenas $19 \%$ afirmaram participar e $62 \%$ não participam das atividades das associações e/ou cooperativas.

Os 19\% que compartilham das atividades das associações, participam das reuniões como membros ou como filhos dos membros associados e tentam desenvolver atividades que estimulem a participação e consolidação dos grupos de juventude: "Faço parte da diretoria como $1^{\circ}$ secretária e também um trabalho voluntário com toda a comunidade, crianças, jovens, adultos e idosos"; “Não sou associada, mas como filha de sócio estou presente nas discussões. Abordando principalmente 0 papel participativo da juventude. Colaboro com as atividades de relatoria e construção de pauta de trabalho para os associados"; "Fazemos grupos de estudos, reunião e encontros com a juventude".

Ainda há aqueles que afirmam que falta interesse em agregar junto ao movimento de juventude por parte dos próprios jovens dos assentamentos: “Lá há várias oportunidades de conhecimento através da associação sobre curso, mas muita gente não se interessa, e o que me inspira é minhas coordenadoras, através delas comecei a participar dos encontros, palestras e cursos e amo tudo que aprendi com elas”.

Quanto à participação em movimentos sociais, $41 \%$ afirmaram ter contato com algum grupo e $59 \%$ não possui nenhum contato com movimentos sociais. O grupo que afirmou possuir contato com movimentos sociais se divide nas atividades da Comissão Pastoral da Terra (CPT) e do Movimento de Mulheres Camponesas (MMC), alguns ainda integram os dois grupos.

No que diz respeito às pretensões para a vida adulta, $59 \%$ dos respondentes almejam permanecer na comunidade onde moram, $13 \%$ desejam morar em outra cidade do interior do estado, outros $13 \%$ querem mudar-se para a capital do estado, $9 \%$ desejam morar na sede do município e $6 \%$ querem mudar-se do estado.

As principais justificativas dos que desejam sair do assentamento são a falta de oportunidades e a dificuldade em se estudar para conseguir um bom emprego e uma boa qualidade de vida morando lá: "Aqui não temos muitas oportunidades de estudo, o máximo é concluir o ensino médio, se quisermos algo a mais temos que ir pra Maceió. Se eu for estudar na capital tenho que morar lá ou então pagar transporte”.

As escolhas referentes às profissões que desejam seguir são diversas, destacando-se as áreas de comércio, que atraem 19\% dos jovens, educação e saúde, ambas correspondendo a 16\% do interesse, artistas ou esportistas correspondem a $9 \%$, profissões técnicas e ser dona (o) de casa correspondem a $6 \%$ do interesse. 
Quando questionados sobre o que seria necessário para que conseguissem alcançar seus objetivos profissionais, muitos jovens apontam o investimento em educação e a necessidade de articulação do poder público para melhoria de oportunidades para esta juventude, como disponibilizar condições de deslocamento, tornando possível o ingresso em uma universidade, por exemplo, e conseguirem mudar a realidade o próprio local onde moram. Outros citam "empenho", "vontade”, "oportunidade" e "dedicação" como pré-requisitos. 0 dinheiro e conciliar o trabalho no lote com o estudo também são fatores importantes:

\section{Investimento na educação;}

Mais investimento do Estado em educação, saúde e assistência social pública interligadas às políticas públicas de qualidade e respectivos ao desenvolvimento ideológico social-participativo trabalho de formação para além do mercado de trabalho focado numa práxis transformadora sem opressões e hegemonia de classes. Onde possamos todas sermos reconhecidas como agentes transformadores;

Não apenas para mim mais para todos que moramos aqui é preciso apoio, tanto municipal agrário e comunidade. Formar para que possamos ficar em loco com o trabalho de base e cuidar da terra; plantar; cuidar; colher e repartir!

Trabalhar para poder pagar um curso, fazer vestibular. Seria necessário que a prefeitura disponibilizasse transporte;

Eu acho que é pouco recurso aqui pra ter que estudar fazer uma faculdade boa, pra depois ter um emprego bom morando aqui, eu acho um pouco difícil em questão ao trabalho (na roça) também. Tipo só estudar não dá, tem que estudar e trabalhar ao mesmo tempo. Fica um pouco difícil.

Mesmo com o descaso do serviço público e as dificuldades enfrentadas relatadas pelos jovens, $62 \%$ acreditam ser possível alcançar seus objetivos pessoais, morando no assentamento.

\section{CONSIDERAÇÕES FINAIS}

Foi possível observar nesta pesquisa o baixo nível de escolaridade dos informantes, tendo em vista que de um total de 20 jovens com faixa etária entre 18 e 29 anos, apenas um ingressou no ensino superior. Apesar do trabalho apresentado ser um pequeno recorte de uma realidade regional, ele reafirma os dados indicados no referencial teórico, que expõe em porcentagens censitárias o baixo nível educacional nacional e estadual quando se fala de áreas rurais.

Há uma baixa perspectiva de aumento da escolaridade e produção de renda no meio rural que é conflitante com o alto desejo de permanência desses jovens em sua comunidade. A falta da implementação de políticas públicas por parte dos governantes dos municípios para as comunidades faz com que cerca de $56 \%$ desses jovens, que são aqueles que almejam o ensino superior, se sintam incapacitados de atingir este objetivo.

Apesar da existência de incentivos nacionais por parte da Secretaria Especial de Agricultura Familiar e do Desenvolvimento Agrário (SEAD) e da Secretaria Nacional da Juventude (SNJ), na esfera 
municipal e comunitária, estes jovens não vislumbram tais meios de produção de renda e acesso à terra dentro das suas comunidades.

Abramovay e outros autores (2001) discutem esta questão, relacionando-a justamente à falta de formação educacional que auxiliaria no próprio exercício da cidadania do individuo,

[...] é evidente que uma política fundiária voltada a estas regiões e a agricultores na faixa etária entre 18 e 30 anos terá que associar-se a métodos alternativos aos da educação formal para que o acesso à terra venha de par com uma melhora em suas capacidades profissionais. (ABRAMOVAY et al., 2001, p. 7).

É imprescindível, como já foi identificado pelos próprios jovens, investimento em capital intelectual, que advém do investimento em educação, que é um dos itens primordiais na construção de uma sociedade pensante e participativa.

Faz-se necessário, também, o aumento da participação política ativa desta juventude dentro de sua própria comunidade, nas associações de moradores e/ou cooperativas. De um total de 32 informantes, apenas 7 possuem algum tipo de participação nestas instituições, dado que faz com que seja questionada a sucessão geracional da família camponesa e a renovação das lideranças destes grupos, como é apontado por Souza e Simonetti (on-line).

Necessita-se, primeiro, o fortalecimento político ativo in loco, dentro das comunidades, para que haja o empoderamento desta juventude, pois estes apresentam uma baixa representatividade político social dentro da comunidade. Este estímulo é imprescindível para que eles possam se fortalecer dentro de suas próprias identidades e cobrarem dos representantes políticos, nas esferas municipais, estaduais e nacionais, o fortalecimento e o exercício de políticas públicas que facilitem a transformação do seu espaço, a comunidade, em um espaço ativo e atuante.

A discussão sobre a sucessão familiar e os padrões sucessórios leva a refletir sobre o futuro da agricultura familiar como um todo. Os estudos mostram a importância do jovem no meio rural, na reprodução dos costumes e tradições e a necessidade de mudanças que devem ocorrer tanto na organização social e econômica das unidades de produção, como na criação de políticas públicas que contemplem a juventude, pois o jovem rural deve ser percebido e caracterizado acima de tudo enquanto jovem, sujeito a influências sociais do atual contexto em que se encontra na sociedade moderna e não como sujeito alheio e isolado do momento histórico social em que está inserido.

Ademais, os jovens devem ser vistos como agentes transformadores do espaço social que habitam. Os pilares do desenvolvimento camponês e agroecológico se sustentam na capacidade de justiça social e desenvolvimento do meio agrário, possibilitando a soberania alimentar e a produção de base familiar. Para alcançar estes objetivos é necessário o empoderamento juvenil no campo e apresentar condições necessárias para o desenvolvimento. 


\section{REFERÊNCIAS}

ABRAMOVAY, Ricardo. Agricultura familiar e desenvolvimento territorial. Reforma Agrária - Revista da Associação Brasileira de Reforma Agrária, v. 28, n. 1, jan./ago. 1999.

ABRAMOVAY, Ricardo et al. Agricultura familiar e sucessão profissional: novos desafios. Anais[...], Brasília: SOBER, 2001.

BRUMER, Anita. A problemática dos jovens rurais na pós-modernidade. In: Congreso Latinoamericano de Sociología Rural, 7, 2006, Quito (Equador). Anales [], 2006.

CPT - Comissão Pastoral da Terra. 2019. Disponível em: https://www.cptnacional.org.br/sobre- nos/ historico. Acesso em: 28 jun. 2019.

IBGE - Instituto Brasileiro de Geografia e Estatística. Censo de 2010. 2010. Disponível em: https:// biblioteca.ibge.gov.br/visualizacao/livros/liv49230.pdf. Acesso em: 28 jun. 2019.

IBGE - Instituto Brasileiro de Geografia e Estatística. Resultados preliminares do censo agropecuário de 2017. 2017. Disponível em: https://censos.ibge.gov.br/agro/2017/resultadoscenso-agro-2017.html. Acesso em: 28 jun. 2019.

MDA - Ministério de Desenvolvimento Agrário. 2018. Disponível em: http://www.mda.gov.br/ sitemda/noticias/agricultura-familiar-do-brasil-\%C3\%A9- 8\%C2\%AA-maior-produtora-dealimentos-do-mundo. Acesso em: 28 jun. 2019.

MDA - Ministério de Desenvolvimento Agrário. 2017. Disponível em: http://www.mda.gov.br/ sitemda/noticias/brasil-70-dos-alimentos-que-v\%C3\%A30-\%C3\%A0- mesa-dos-brasileiross\%C3\%A3o-da-agricultura-familiar. Acesso em: 28 jun. 2019.

SEPLAG - Secretaria do Planejamento, Gestão e Patrimônio de Alagoas. Estudo sobre a agricultura familiar em Alagoas. 2016. Disponível em: http://dados.al.gov.br/dataset/39e70e254d9c-4680-b9e8-d709de9f0f94/resource/bc6e26ad-d1ad-410e-baf7-9da145bffa55/download/ estudo03agriculturafamiliar.pdf. Acesso em: 28 jun. 2019.

SOUZA, Bruno Lacerra de; SIMONETTI, Mirian Lourenção. Juventude rural: a construção de um conceito. Disponível em:https://www.uniara.com.br/legado/nupedor/nupedor_2014/ Arquivos/02/2A/9_Bruno\%20Lace rra.pdf. Acesso em: 28 jun. 2019. 
WEISHEIMER, Nilson. A situação juvenil na agricultura familiar. 2009. Tese (Doutorado em Sociologia) - Universidade Federal do Rio Grande do Sul, Porto Alegre, RS, 2009. 
1 Doutora em Sociologia - UFPB; Mestre em Sociologia e graduada em Ciências Sociais - UFPE; Professora do Instituto Federal de Alagoas - IFAL, campus Murici.

E-mail: gessikacecilia@hotmail.com

2 Técnica em Agroecologia - IFAL, campus Murici; Graduanda em Agronomia - UFAL.

E-mail: mariaeduardacosta54@hotmail.com

\section{(9) (1) (-)}

Este artigo é licenciado na modalidade acesso abertosob a Atribuição-Compartilhalgual CC BY-SA

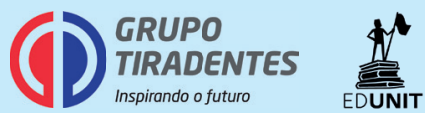

